\begin{tabular}{|c|l|}
\hline Title & $\begin{array}{l}\text { Development of a loop-mediated isothermal amplification method for rapid mass screening of sand flies for Leishmania } \\
\text { infection }\end{array}$ \\
\hline Author(s) & $\begin{array}{l}\text { Nzelu, Chukwunonso O.; Gomez, Eduardo A.; Cáceres, A braham G.; Sakurai, Tatsuya; Martini-Robles, Luiggi; U Uzato, } \\
\text { Hiroshi; Mimori, Tatsuyuki; Katakura, Ken; Hashiguchi, Y oshihisa; Kato, Hirotomo }\end{array}$ \\
\hline Citation & $\begin{array}{l}\text { Acta Tropica, 132, 1-6 } \\
\text { https://doi.org/10.1016/.actatropica.2013.12.016 }\end{array}$ \\
\hline Issue Date & 201404 \\
\hline Doc URL & http:/hdl.handle.net/2115/54556 \\
\hline Type & article (author version) \\
\hline File Information & LAMP manuscript-revise.pdf \\
\hline
\end{tabular}

Instructions for use 


\section{Development of a loop-mediated isothermal amplification method for rapid mass-screening of sand flies for Leishmania infection}

Chukwunonso O. Nzelu ${ }^{\mathrm{a}}$, Eduardo A. Gomez ${ }^{\mathrm{b}}$, Abraham G. Cáceres ${ }^{\mathrm{c}, \mathrm{d}}$, Tatsuya Sakurai ${ }^{\mathrm{a}}$, Luiggi Martini-Robles $^{\mathrm{e}}$, Hiroshi Uezato ${ }^{\mathrm{f}}$, Tatsuyuki Mimori ${ }^{\mathrm{g}}$, Ken Katakura ${ }^{\mathrm{a}}$, Yoshihisa Hashiguchi ${ }^{\mathrm{h}, \mathrm{Ij}}$, Hirotomo Kato ${ }^{\mathrm{a}, *}$

${ }^{a}$ Laboratory of Parasitology, Department of Disease Control, Graduate School of Veterinary Medicine, Hokkaido University, Sapporo, Japan

${ }^{\mathrm{b}}$ Servicio Nacional de Erradicacion de la Malaria (SNEM), Ministerio de Salud Publica, Ecuador

'Departamento Académico de Microbiología Médica, Facultad de Medicina Humana, Universidad Nacional Mayor de San Marcos, Lima, Peru

${ }^{\mathrm{d}}$ Laboratorio de Entomología, Instituto Nacional de Salud, Lima, Peru,

${ }^{\text {e}}$ Departamento de Parasitologia, Instituto Nacional de Higiene y Medicina Tropical ‘Leopoldo Izquieta Perez', Ecuador

${ }^{\mathrm{f}}$ Department of Dermatology, Faculty of Medicine, University of the Ryukyus, Okinawa, Japan

${ }^{\mathrm{g}}$ Department of Microbiology, Faculty of Life Sciences, Graduate School of Health Sciences, Kumamoto University, Kumamoto, Japan

${ }^{\mathrm{h}}$ Department of Parasitology, Kochi Medical School, Kochi University, Kochi, Japan

${ }^{\mathrm{i} C e n t r o ~ d e ~ B i o m e d i c i n a, ~ U n i v e r s i d a d ~ C e n t r a l ~ d e l ~ E c u a d o r, ~ Q u i t o, ~ E c u a d o r ~}$ 
${ }^{\mathrm{j}}$ Prometeo, Secretaría Nacional de Educacion Superior, Ciencia, Tecnologia e Innovacion (SENESCYT), Ecuador

*Corresponding author: Hirotomo Kato, Laboratory of Parasitology, Department of Disease

Control, Graduate School of Veterinary Medicine, Hokkaido University, North 18 West 9, Kita-ku,

Sapporo, Hokkaido, 060-0818, Japan.

Phone \& Fax: +81-11-706-5196.

E-mail address: hkato@vetmed.hokudai.ac.jp 


\begin{abstract}
Entomological monitoring of Leishmania infection in leishmaniasis endemic areas offers epidemiologic advantages for predicting the risk and expansion of the disease, as well as evaluation of the effectiveness of control programs. In this study, we developed a highly sensitive loop-mediated isothermal amplification (LAMP) method for the mass screening of sand flies for Leishmania infection based on the 18S rRNA gene. The LAMP technique could detect 0.01 parasites, which was more sensitive than classical PCR. The method was robust and could amplify the target DNA within $1 \mathrm{hr}$ from a crude sand fly template without DNA purification. Amplicon detection could be accomplished by the newly developed colorimetric malachite green (MG)mediated naked eye visualization. Pre-addition of MG to the LAMP reaction solution did not inhibit amplification efficiency. The field applicability of the colorimetric MG-based LAMP assay was demonstrated with 397 field-caught samples from the endemic areas of Ecuador and 8 positive sand flies were detected. The robustness, superior sensitivity, and ability to produce better visual discriminatory reaction products than existing LAMP fluorescence and turbidity assays indicated the field potential usefulness of this new method for surveillance and epidemiological studies of leishmaniasis in developing countries.
\end{abstract}

Keywords: Leishmania; sand fly; malachite green; loop-mediated isothermal amplification (LAMP) 


\section{Introduction}

Leishmaniasis is a vector-borne parasitic disease caused by an obligate intracellular protozoan of the genus Leishmania. It is one of the most neglected diseases worldwide, distributed especially in tropical and subtropical areas, and it has strong and complex associations with poverty (Alvar et al., 2006). Leishmania parasites cause three forms of leishmaniases (cutaneous, mucocutaneous and visceral leishmaniasis) depending on the infecting species. The protozoan is transmitted by the bite of an infected female sand fly of the genus Phlebotomus in the Old World and Lutzomyia in the New World (Munstermann, 2004; Kato et al., 2010). The spread of leishmaniasis largely depends on the distribution of sand fly vectors. Approximately 800 sand fly species have been described, but only a few are medically important (Munstermann, 2004, Kato et al., 2010).

The monitoring of natural Leishmania infection in sand fly populations is an important epidemiological parameter for predicting the risk and prevalence of disease, the estimation of which depends on the reliable identification of infected sand flies. Estimation of Leishmania infection rates in the vector could serve as an indicator of a change in transmission intensity at a given endemic area. Such studies have been conducted either by dissecting individual insects and detecting the parasites under a microscope, or polymerase chain reaction (PCR)-based techniques to detect Leishmania DNA in sand flies (Kato et al., 2005). The former is laborious and timeconsuming due to the low Leishmania infection rate in sand flies in most endemic areas (Aransay et al., 2000; Kato et al., 2005). The latter method has been proved to have both high sensitivity and specificity; however, the PCR methods require specialized instruments and take several hours, which make their use in resource-limited countries and under field conditions unfeasible. There is therefore a need for a simplified method of amplification and amplicon detection that can 
complement the available surveillance tools and generate information on the distribution or expansion of the disease.

As an alternative, the loop-mediated isothermal amplification (LAMP) technique may provide an answer to vector monitoring needs. This technique has been proven to be an accurate, rapid and simple method, which amplifies the target nucleic acid under isothermal conditions (Notomi et al., 2000). Recently, wide applicability of LAMP in the detection of parasitic protozoa such as Babesia, Plasmodium, Leishmania and Trypanosoma in clinical samples has been demonstrated (Ikadai et al., 2004; Poon et al., 2006; Njiru et al., 2008; Takagi et al., 2009; Thekisoe et al, 2007; Laohasinnarong et al., 2011). Studies have also shown the application of LAMP to survey vectors of infectious diseases (Aonuma et al., 2009; Thekisoe et al., 2010; Nakao et al., 2010); however, these studies used purified DNA as a template for the LAMP assays. The use of a DNA extraction kit and the time-consuming DNA purification process in template preparation reduces the utility of LAMP technique as a surveillance tool for mass screening of infected vectors with pathogens in endemic regions. To date, no reports have been available on the use of the LAMP method for detection of Leishmania-infected sand flies. Considering these points, we developed and validated a novel LAMP assay for mass screening of sand fly vectors for Leishmania infection. In this study, a newly developed LAMP method for rapid detection of the Leishmania DNA within sand fly vectors is described, in addition to the use of a non-fluorescent cationic dye, namely, malachite green (MG) for the first time as a simpler colorimetric assay for the detection of LAMP reactions. The present method was evaluated with field-captured sand fly samples in order to demonstrate its efficacy and reliability as an important potential tool in assessing Leishmania infection and/or transmission intensity in endemic areas of Ecuador. 


\section{Materials and methods}

\subsection{Sand fly collection}

Wild sand flies were collected in March, July and August 2012 in Andean areas of Ecuador; Alausi, Chanchan and Huigra (Province of Chimborazo), where Andean-type cutaneous leishmaniasis caused by Leishmania (Leishmania) mexicana is endemic (Kato et al., 2005, 2008). Sand flies were caught using protected human bait, CDC light traps and Shannon traps. The collected sand flies were dissected and then identified at the species level mainly based on the morphology of their spermathecae (Young and Duncan, 1994). These flies were examined for Leishmania infection by microscopy. To validate the newly developed LAMP method, sand fly collections were also made at the same areas using the capture methods mentioned above. These flies were fixed in absolute ethanol and stored at room temperature.

\subsection{DNA preparation}

DNA samples used in this study were prepared from the following Leishmania reference strains: L. (L.) major-like (MHOM/EC/1988/PT-115), L. (L.) mexicana (MNYC/BZ/1962/M379), L. (L.) amazonensis (MHOM/BR/1973/M2269), L. (Viannia) guyanensis (MHOM/BR/1975/M4147), L. (V.) braziliensis (MHOM/BR/1975/M2904) and L. (V.) panamensis (MHOM/PA/1971/LS94) in the New World, and L. (L.) major (MHOM/SU/1973/5ASKH), L. (L.) tropica (MHOM/SU/1958/strainOD), L. (L.) infantum (MHOM/ES/1993/PM1), L. (L.) donovani (MHOM/SU/1962/25-25M-C2) in the Old World. DNA from Leishmania-related parasites capable of infecting sand flies, such as Endotrypanum (Kato et al., 2007) and anuran Trypanosoma species (Ferreira et al., 2008), and also DNA from the sand flies Phlebotomus papatasi and Lutzomyia ayacuchensis, were included to evaluate the present LAMP primer specificity. 
For sand fly crude DNA extraction, ethanol-fixed sand fly samples were individually lysed in $50 \mu \mathrm{l}$ of DNA extraction buffer [150 mM NaCl, $10 \mathrm{mM}$ Tris- $\mathrm{HCl}$ (pH8.0), $10 \mathrm{mM}$ EDTA and $0.1 \%$ sodium dodecyl sulfate (SDS)] in the presence of proteinase $\mathrm{K}(100 \mu \mathrm{g} / \mathrm{ml})$ without homogenization. The samples were incubated overnight at $37{ }^{\circ} \mathrm{C}$. After $25 \mu 1$ of distilled water was added, the samples were preheated at $95{ }^{\circ} \mathrm{C}$ for $5 \mathrm{~min}$, and $1 \mu \mathrm{l}$ was directly used as a template for the LAMP method.

\subsection{Polymerase chain reaction amplification}

Conventional PCR was performed with previously described primers specific for Leishmania minicircle kinetoplast DNA (mkDNA) (Kato et al., 2005, 2007). The primer sequences used for amplification were $5^{\prime}$-CTRGGGGTTGGTGTAAAATAG- $3^{\prime}$ (L.MC-1S) and $5^{\prime}$ TWTGAACGGGRTTTCTG- 3' (L.MC-1R) (Kato et al., 2005). The reaction was carried out in a volume of $15 \mu \mathrm{l}$ using a pair primers $(0.4 \mu \mathrm{M}$ each) and 2 x Ampli Taq Gold PCR Master Mix (Applied Biosystems, NJ, USA). After an initial denaturation at $95{ }^{\circ} \mathrm{C}$ for $10 \mathrm{~min}$, PCR amplification was performed with 30 cycles of denaturation $\left(95^{\circ} \mathrm{C}\right.$, for $\left.1 \mathrm{~min}\right)$, annealing $\left(55^{\circ} \mathrm{C}\right.$, for $1 \mathrm{~min}$ ), and polymerization $\left(72{ }^{\circ} \mathrm{C}, 1 \mathrm{~min}\right)$, followed by a final extension at $72{ }^{\circ} \mathrm{C}$ for $10 \mathrm{~min}$. The PCR products were resolved by agarose gel electrophoresis.

To identify sand fly by PCR-restriction fragment length polymorphism (PCR-RFLP), PCR amplification with Lutzomyia 18S rRNA gene-specific primers and subsequent digestion with the Afa I enzyme were performed as previously described (Kato et al., 2007, 2008).

\subsection{Loop-mediated isothermal amplification method}


Sets of forward and backward external primers (F3 and B3) and forward and backward internal primers (FIP and BIP) were designed using PrimerExplorer version 4.0 software (http://primerexplorer.jp/elamp4.0.0) based on the conserved region of the Leishmania 18S ribosomal RNA (rRNA) gene. We considered this region to be appropriate because of its conservation across Leishmania species. Selection of primers used required a number of preliminary LAMP experiments for optimization. Selected LAMP primers are shown in Table 1. The LAMP assay was conducted in $15 \mu \mathrm{l}$ of a reaction mixture consisting of a $1.6 \mu \mathrm{M}$ concentration of each inner primer (FIP and BIP), a $0.2 \mu \mathrm{M}$ concentration of each outer primer (F3 and B3), 1 x reaction mix (Eiken, Tochigi, Japan), $8 \mathrm{U}$ Bst DNA polymerase (Eiken), 0.004\% malachite green (MG) dye (dissolved in distilled water), and $1 \mu 1$ of template DNA. The mixture was incubated at $64{ }^{\circ} \mathrm{C}$ for $60 \mathrm{~min}$ in a heating block and then heated at $80{ }^{\circ} \mathrm{C}$ to terminate the reaction. A positive control (DNA from a reference stain: L. (V.) braziliensis MHOM/BR/1975/M2904) and a negative (water) sample were included in each LAMP assay. At the end of incubation, the amplification of the target DNA was confirmed based on direct visual inspection of the reaction tubes by the naked eye; a positive amplification showed as light blue, whereas in the absence of amplification, the reaction mixture became colorless. For further confirmation, $2 \mu 1$ of each LAMP product were subjected to electrophoresis on $2.5 \%$ agarose gels and visualized.

To determine the analytical sensitivity of the LAMP test, 10-fold serial dilutions of purified $L$. (L.) mexicana (MNYC/BZ/62/M379) and L. (L.) major-like (MHOM/EC/88/PT-115) DNA (equivalent to $10^{4}$ to 0.01 parasites) were used as a template. Additionally, 0.1 and 0.01 parasite DNA mixed with crude sand fly extract were used as a template to test the detection sensitivity of the newly developed LAMP method in crude extract. Furthermore, LAMP assay was performed 
using crude sand fly DNA samples naturally infected with $L$. (L.) mexicana and $L$. (V.) naiffi to confirm the assay amplification efficiency.

\subsection{DNA sequencing}

The LAMP products were purified using a PCR purification kit (Qiagen, Valencia, CA) and then sequenced with FIP and BIP primers (Table 1) using a BigDye Terminator version 3.1 Cycle-Sequencing Kit (Applied Biosystems, Foster City, CA). Furthermore, in order to confirm the Leishmania species within the LAMP-positive sand flies, PCR amplification was performed with primers specific for Leishmania cytochrome $b \quad\left(\begin{array}{ll}c y t & \text { b) L.cyt-S: }\end{array} 5^{\prime}-\right.$ GGTGTAGGTTTAGTYTAGG-3' and L.cyt-R: CTACAATAAaCAAATCATAATATRCAATT- 3’ using Ampdirect Plus (Shimadzu Biotech, Tsukuba, Japan) as previously described (Kato et al 2005, 2007). The products were cloned into the pGEM-T Easy Vector System (Promega, Madison, WI) and sequences were determined by the dideoxy chain termination method using a BigDye Terminator Cycle-Sequencing Kit (Applied Biosystems). 


\section{Results}

\subsection{Sensitivity and specificity of LAMP}

Successful amplification reactions with I8S rRNA Leishmania LAMP primers (Table 1) were achieved in sample tubes containing each target DNA. The LAMP results were identical when a thermal-cycler, water bath and the heating block were used as the source of heat. The sensitivities of the broad range LAMP assay were assessed with serial dilutions of $L$. $(L$.$) mexicana and L .(L$. major-like DNA ( $10^{4}$ to 0.01 parasites). The LAMP assay was able to detect all the broad range concentrations tested, while no amplification was detected in the negative control. The results were visually discriminated. All samples containing DNA of Leishmania parasites turned light blue, whereas the negative samples turned from green to colorless after the LAMP reaction without adding any reagent. (Fig. 1A). In agreement with the new colorimetric LAMP method using DNA intercalating malachite green dye, gel electrophoresis also showed that 0.01 Leishmania parasites is sufficient for LAMP detection (Fig. 1B). The results of all the positive samples detected by the LAMP assay were achieved within $60 \mathrm{~min}$. The comparative sensitivities of the LAMP and mkDNA PCR assays revealed that the LAMP assay was more sensitive than the mkDNA PCR assay, which has a detection limit of $0.1-1$ parasites, corresponding to a previous report (Kato et al, 2005). The sensitivity of the LAMP assay was found to be the same for both the $L$. (L.) mexicana and $L$. (L.) major-like strains tested in this study. The LAMP assay was able to amplify all the New and Old World human pathogenic Leishmania species tested and no reactivity was recorded from the anuran Trypanosoma sp., P. papatasi and/or Lu. ayacuchensis sand fly vectors, cross reacted with Endotrypanum, a non-pathogenic to humans, but sand fly parasitic protozoa, in the New World (Fig. 2A and B). 
We observed that LAMP could reliably be used to amplify Leishmania DNA directly from crude infected sand fly extract, and had high detection sensitivity down to levels of 0.1 and 0.01 parasites (data not shown). This result indicated the ability of the LAMP assay to withstand the inhibitory effects of components present in the crude sand fly extracts and still show high detection sensitivity.

3.2. Evaluation of LAMP for mass screening of sand flies from areas where leishmaniasis is endemic

In order to evaluate the field utility of the newly established LAMP method, we applied the technique to sand flies caught from leishmaniasis endemic areas of Eucuador. A total of 397 sand flies (192, 68 and 137 samples from Huigra, Chanchan and Alausi, respectively) were individually screened for Leishmania infection (Table 2). LAMP amplicons were directly detected in 8 samples (3 from Chanchan, 5 from Alausi). No Leishmania DNA was detected in any Huigra samples by the LAMP method. This observation corresponded with the results obtained from the microscopic examination of sand flies for Leishmania promastigotes in the same areas (Table 2). The LAMP results confirmed the applicability of this new field-based, MG-based-LAMP detection assay using crude extract as templates, and without gel electrophoresis in endemic areas, thereby reducing the cost and turnaround time for the LAMP method. The accuracy of the LAMP amplicons was confirmed by direct sequencing with inner primers wherein the sequences obtained showed greater homologies with 18S rRNA genes from Leishmania species registered in GeneBank (data not shown). For further confirmation of the Leishmania species within LAMPpositive flies, leishmanial cyt $\mathrm{b}$ gene was analyzed for identification at the species level. The $c y t \mathrm{~b}$ genes from the eight LAMP-positive samples were successfully amplified by PCR and the 
sequences were determined. The gene sequences of all the positive samples (GenBank accession numbers: AB847149-AB847156) had the highest degree of homology with the cyt b gene of $L$. (L.) mexicana $(98.0-99.0 \%)$ when compared with those of other species $(88.0-97.0 \%)$. This result indicated that the Leishmania DNA detected by the LAMP method within individual sand flies caught from Alausi and Chanchan were all L. (L.) mexicana, corresponding to the previous reports from the same areas (Kato et al, 2005, 2008). In addition, based on PCR-RFLP analysis of sand fly $18 \mathrm{~S}$ rRNA with Afa I endonuclease digestion (Kato et al., 2007, 2008), all the LAMPpositive flies were identified as Lutzomyia ayacuchensis (Table 2), a proven and sole vector of $L$. (L.) mexicana in both Alausi and Chanchan, as well as other Andean endemic areas of Ecuador (Takaoka et al., 1990; Kato et al., 2005, 2008). 


\section{Discussion}

Monitoring of infection in the vector sand fly population is an essential tool for surveillance of infections and identification of the vector species. The mass screening of sand flies for Leishmania infection has the potential to provide insight into the current transmission of the infection in endemic areas. In this study, we demonstrated the detection of Leishmania DNA within sand fly vectors using a newly developed LAMP method based on the 18S rRNA gene. The LAMP method is rapid, reliable and amplification of all Leishmania species in one test is achieved within 60 min using a normal water bath or heating block, obviating the need for a thermal cycler. The recorded analytical sensitivity of 0.01 Leishmania parasites indicates the applicability of this method, not only for detection of vector samples, but also that of clinical cases with extremely low parasite burden.

One of the most attractive features of the newly developed LAMP assay is that it has a great advantage in terms of amplicon detection by simple MG dye-mediated naked eye visualization. The detection method can be accomplished in a closed system without opening reaction tubes or post-amplification handling; a contamination prone step is completely avoided due to pre-addition of the MG in the LAMP reaction. As the MG signal recognition is highly sensitive, this system enables visual discrimination of results without costly specialized equipment and the use of a dangerous UV illuminator or light box, while interpretation by an independent observer is not required. The change of color is permanent and thus can be kept for record purposes. This new detection method could be helpful for high-throughput DNA detection in basic research and pointof-care testing. Several studies have used LAMP assays for detecting various pathogens, but mostly using a real-time turbidimeter (Parida et al., 2007; Yoneyama et al., 2007; Toriniwa et al., 2006; Thekisoe et al., 2010), a real-time PCR system (Cai et al., 2008; Ohtsuki et al., 2008) or 
fluorescent detection reagents (FDR) (Eiken) (Adams et al., 2010), which require a UV illuminator for LAMP product discrimination. The use of expensive and specialized equipment reduces the versatility of LAMP and greatly limits the wide use of this technique, especially in developing countries. Malachite green is very cheap, easy to prepare and does not require freezing for storage. To our knowledge, this is the first report of using MG dye to visualize LAMP products. The visual assessment of LAMP products using MG dye is reproducible, robust and consistent. Significantly, MG does not interfere with DNA synthesis by Bst DNA polymerase. This wider working flexibility makes MG an effective, straightforward field colorimetric detection dye in LAMP studies.

The potential usefulness of the LAMP method as a field-friendly molecular surveillance tool is demonstrated by the ability of the new assay to amplify the target DNA from crude DNA extract without the expensive and time-consuming process of DNA purification. More promising is the ability of the LAMP method to overcome potential inhibitors in crude sand fly templates, an issue of particular concern for PCR assays, and still not compromise its detection sensitivity down to levels of 0.1 and 0.01 parasites. It is suggested that a significant amount of parasite DNA is lost during the extraction process, resulting in a lower detection limit when purified DNA is used as a template (Njiru et al., 2011). Other studies have shown superior tolerance of LAMP tests for biological substances (Kaneko et al., 2007; Poon et al., 2006). We observed uncompromising detection sensitivity of LAMP, as well as amplification consistency of the target DNA from crude sand fly DNA extracts stored at $-20^{\circ} \mathrm{C}$ for months, indicating the stability of the target DNA.

In the present study, the applicability of the colorimetric MG-based LAMP assay for detection of Leishmania DNA in sand flies as a field diagnostic and surveillance tool was validated with 397 wild-caught sand flies. The mass screening of sand flies from the three endemic areas, Huigra, 
Chanchan and Alausi, resulted in the detection of eight Leishmania 18S rRNA DNA-positive sand flies. The eight positives were confirmed to be Leishmania DNA by direct sequencing of the LAMP products and further identified to the species level as $L$. (L.) mexicana based on cyt b gene sequencing analysis of the PCR amplicons. Furthermore, we showed that these LAMP Leishmania DNA-positive flies were all Lutzomyia ayacuchensis by PCR-RFLP of their 18S rRNA gene fragment patterns. This result was consistent with previous reports from the same study areas (Hashiguchi et al., 1991; Kato et al., 2005, 2008). Hence, in this proof-of-concept study, the LAMP method using MG dye was found to be a rapid, sensitive and high-throughput screening tool for the detection of sand flies infected with the Leishmania DNA in endemic areas. At best, it allows for an immediate real-time assessment of the presence of Leishmania parasites in endemic communities. The test is robust and amplification of Leishmania DNA directly from sand fly crude extract can be achieved using a normal water bath or heating block without compromising the test sensitivity.

Taken together, our successful detection of Leishmania DNA in field-caught sand flies demonstrated the applicability of the LAMP assay in the surveillance of Leishmania parasites in sand fly vectors in areas where leishmaniasis is endemic. The developed colorimetric LAMP method using MG will not only make an excellent surveillance tool, but also a very rapid, reliable and highly sensitive field diagnostic test which will be widely applicable for vectors, reservoirs and humans in resource-limited endemic countries. 


\section{Acknowledgements}

We are indebted to Kazue Hashiguchi (Centro de Biomedicina, Universidad Central del Ecuador), Flavio-Valeriano Zambrano C. (Servicio Nacional de Erradicacion de la Malaria, Guayaquil, Ecuador) and Roberto Sud A. (Ministerio de Salud Publica y Asistencia Social, Guayaquil, Ecuador) for their technical assistance during the field phase of the present study. This study was financially supported by the Ministry of Education, Culture, Sports, Science and Technology (MEXT) of Japan (Grant Nos. 25257501 and 23256002), the Program for Leading Graduate Schools "Fostering Global Leaders in Veterinary Science for Contributing to One Health" (FO1), MEXT, Japan, the Monbukagakusho (MEXT), Japan and the Prometeo Project of the Secretaria Nacional de Educacion Superior, Ciencia, Tecnologia e Innovacion (SENESCYT), Ecuador. 


\section{References}

Adams, E.R., Schoone, G.J., Ageed, A.F., Safi, S.E., Schallig, H.D., 2010. Development of a reverse transcriptase loop-mediated isothermal amplification (LAMP) assay for the sensitive detection of Leishmania parasites in clinical samples. Am. J. Trop. Med. Hyg. 82, 591-596.

Alvar, J., Yactayo, S., Bern, C., 2006. Leishmaniasis and poverty. Trends Parasitol. 22, 552-557.

Aransay, A.M., Scoulica, E., Tselentis, Y., 2000. Detection and identification of Leishmania DNA within naturally infected sand flies by seminested PCR on minicircle kinetoplastic DNA. Appl. Environ. Microbiol. 66, 1933-1938.

Aonuma, H., Yoshimura, A., Perera, N., Shinzawa, N., Bando, H., Oshiro, S., Nelson, B., Fukumoto, S., Kanuka, H., 2009. Loop-mediated isothermal amplification applied to filarial parasites detection in the mosquito vectors: Dirofilaria immitis as a study model. Parasite Vectors. 2, 15.

Cai, T., Lou, G., Yang, J., Xu, D., Meng, Z., 2008. Development and evaluation of real-time loopmediated amplification for hepatitis B virus DNA quantification: a new tool for HBV management. J. Clin. Virol. 41, 270-276.

Ferreira, R.C., De Souza, A.A., Freitas, R.A., Campaner, M., Takata, C.S., Barrett, T.V., Shaw, J. J., Teixeira, M.M., 2008. A phylogenetic lineage of closely related trypanosomes (Trypanosomatide, Kinetoplastida) of anurans and sand flies (Psychodidae, Diptera) sharing the same ecotopes in Brazilian amazonia. J. Eukaryot Microbiol. 55, 427-435.

Hashiguchi, Y., Gomez, E.A., de Coronel, V.V., Mimori, T., Kawabata, M., Furuya, M., Nonaka, S., Takaoka, H., Alexander, J.B., Quizhpe, A.M., Grimaldi, G.Jr., Kreutzer, R.D., Tesh, R.B., 
1991. Andean leishmaniasis in Ecuador caused by infection with Leishmania mexicana and $L$. major-like parasites. Am. J. Trop. Med. Hyg. 44, 205-217.

Ikadai, H., Tanaka, H., Shibahara, N., Matsuu, A., Uechi, M., Itoh, N., Oshiro, S., Kudo, N., Igarashi, I., Oyamada, T., 2004. Molecular evidence of infections with Babesia gibsoni parasites in Japan and evaluation of the diagnostic potential of a loop-mediated isothermal amplification method. J. Clin. Microbiol. 42, 2465-2469.

Kaneko, H., Kawana, T., Fukushima, E., Suzutani, T., 2007. Tolerance of loop-mediated isothermal amplification to a culture medium and biological substances. J. Biochem. Biophys. Methods. 70, 499-501.

Kato, H., Uezato, H., Katakura, K., Calvopiña, M., Marco, J.D., Barroso, P.A., Gomez, E.A., Mimori, T., Korenaga, M., Iwata, H., Nonaka, S., Hashiguchi, Y., 2005. Detection and identification of Leishmania species within naturally infected sand flies in the Andean areas of Ecuador by a polymerase chain reaction. Am. J. Trop. Med. Hyg. 72, 87-93.

Kato, H., Uezato, H., Gomez, E.A., Terayama, Y., Calvopiña, M., Iwata, H., Hashiguchi, Y., 2007. Establishment of a mass screening method of sand fly vectors for Leishmania infection by molecular biological methods. Am. J. Trop. Med. Hyg. 77, 324-332.

Kato, H., Cáceres, A.G., Gomez, E.A., Mimori, T., Uezato, H., Marco J.D., Barroso P.A., Gomez E.A., Iwata H., Hashiguchi, Y., 2008. Molecular mass screening to incriminate sand fly vectors of Andean-type cutaneous leishmaniasis in Ecuador and Peru. Am. J. Trop. Med. Hyg. 79, 719-721. 
Kato, H., Gomez, E.A., Cáceres, A.G., Uezato, H., Mimori, T., Hashiguchi, Y., 2010. Molecular epidemiology for vector research on leishmaniasis. Int. J. Environ. Res. Public Health 7, 814826.

Laohasinnarong, D., Thekisoe, O.M., Malele, I., Namangala, B., Ishii, A., Goto, Y., Kawazu, S., Sugimoto, C., Inoue, N., 2011. Prevalence of Trypanosoma sp. in cattle from Tanzania estimated by conventional PCR and loop-mediated isothermal amplification (LAMP). Paraitol. Res. 109, 1735-1739.

Munstermann, L.E., 2004. Phlebotomine sand flies, the Psychodidae. In: Marquardt, W.C., Black, W.C., Freier, J.E., Hagedorn, H.H., Hemingway, J., Higgs, S., James, A.A., Kondratieff, B., Moore, C.G., (Ed.), Biology of Disease Vectors. Second edition. San Diego, CA, Elsevier, pp. $141-151$.

Nakao, R., Stromdahl, E.Y., Magona, J.W., Faburay, B., Namangala, B., Malele, I., Inoue, N. Geysen, D., Kajino, K., Jongejan, F., Sugimoto, C., 2010. Development of loop-mediated isothermal amplification (LAMP) assays for rapid detection of Ehrlichia ruminantium. BMC Microbiol. 10, 296.

Njiru, Z.K., Mikosza, A.S., Matovu, E., Enyaru, J.C., Ouma, J.O., Kinona, S.N., Thompson, R.C., Ndung'u, J.M., 2008. African trypanosomiasis: sensitive and rapid detection of the sub-genus Trypanosoma by loop-mediated isothermal amplification (LAMP) of parasite DNA. Int. J. Parasitol. 38, 589-599.

Njiru, Z.K., Traub, R., Ouma, J.O., Enyaru, J.C., Matovu E., 2011. Detection of Group 1 Trypanosoma brucei gambiensis by loop-mediated isothermal amplification (LAMP). J. Clin. Microbiol. 49, 1530-1536. 
Notomi, T., Okayama, H., Masubuchi, H., Yonekawa, T., Watanabe, K., Amino, N., Hase, T., 2000. Loop-mediated isothermal amplification of DNA. Nucleic Acids Res. 28, E63.

Ohtsuki, R., Kawamoto, K., Kato, Y., Shah, M.M., Ezaki, T., Makino, S.I., 2008. Rapid detection of Brucella spp. by the loop-mediated isothermal amplification method. J. Appl. Microbiol. $104,1815-1823$.

Parida, M.M., Santhosh, S.R., Dash, P.K., Tripathi, N.K., Lakshmi, V., Mamidi, N., Shrivastva, A., Gupta, N., Saxena, P., Babu, J.P., Lakshman Rao, P.V., Morita K., 2007. Rapid and real-time detection of Chikungunya virus by reverse transcription loop-mediated isothermal amplification assay. J. Clin. Microbiol. 45, 351-357.

Poon, L.L., Wong, B.W., Ma, E.H., Chan, K.H., Chow, L.M., Abeyewickreme, W., Tangpukdee, N., Yuen, K.Y., Guan, Y., Looareesuwan, S., Peiris, J.S., 2006. Sensitive and inexpensive molecular test for falciparium malaria: detecting Plasmodium falciparum DNA directly from heat-treated blood by loop-mediated isothermal amplification. Clin. Chem. 52, 303-306.

Takagi, H., Itoh, M., Islam, M.Z., Razzaque, A., Ekram, A.R.M., Hashiguchi, Y., Noiri, E., Kimura, E., 2009. Sensitive, specific and rapid detection of Leishmania donovani DNA by loop-mediated isothermal amplification. Am. J. Trop. Med. Hyg. 81, 578-582.

Takaoka, H., Gomez, E.A., Alexander, J.B., Hashiguchi, Y., 1990. Natural infections with Leishmania promastigotes in Lutzomyia ayacuchensis (Diptera: Psychodidae) in an Andean focus of Ecuador. J. Med. Entomol. 27, 701-702.

Thekisoe, O.M., Kuboki, N., Nambota, A., Fujisaki, K., Sugimoto, C., Igarashi, I., Yasuda, J., Inoue, N., 2007. Species-specific loop-mediated isothermal amplification (LAMP) for diagnosis of trypanosomosis. Acta Trop. 102, 182-189. 
Thekisoe, O.M., Rodriguez, C.V., Rivas, F., Coronel-Servian, A.M., Fukumoto, S., Sugimoto, C., Kawazu, S., Inoue, N., 2010. Detection of Trypanosoma cruzi and T. rangeli infections from Rhodnius pallescens bugs by loop-mediated isothermal amplification (LAMP). Am. J. Trop. Med. Hyg. 82, 855-860.

Toriniwa, H., Komiya, T., 2006. Rapid detection and quantification of Japanese encephalitis virus by real-time reverse transcription loop-mediated isothermal amplification. Microbiol. Immunol. 50, 379-387.

Yoneyama, T., Kiyohara, T., Shimasaki, N., Kobayashi, G., Ota, Y., Notomi, T., Totsuka, A., Wakita, T., 2007. Rapid and real-time detection of hepatitis A virus by reverse transcription loop-mediated isothermal amplification assay. J. Virol. Methods 151, 162-168.

Young, D.G., Duncan, M.A., 1994. Guide to the identification and geographic distribution of Lutzomyia sand flies in Mexico, the West Indies Central and South America (Diptera: Psychodidae). Memoirs of the American Entomological Institute, 54. Associated PublishersAmerican Entomological Institute, Gainsville, FL. 


\section{Figure Legends}

Fig. 1. Sensitivity of LAMP assays for detection of Leishmania DNA using serial dilutions of Leishmania (Leishmania) mexicana (MNYC/BZ/1962/M379). A. Colorimetric visual detection sensitivity of the LAMP assay, using pre-added malachite green dye in a closed reaction system. After incubation at $64{ }^{\circ} \mathrm{C}$ for $60 \mathrm{~min}$, LAMP reactions were inspected visually by the naked eye without a UV illuminator or light box. The light blue color indicates a positive reaction and the colorless product indicates a negative reaction. B. Agarose gel electrophoresis of LAMP products. M: gene ruler.

Fig. 2. Specificity of LAMP assay. A. Visual appearance of malachite green based-LAMP specificity reaction products inspected by the naked eye without UV or ordinary light. The color changes from light blue in the positive reactions to colorless in the negative reactions. B. Specificity of the LAMP assay studied by agarose gel electrophoresis. M: gene ruler; maj: $L$. (L.) major-like; mex: L. (L.) mexicana; ama: L. (L.) amazonensis; guy: L. (V.) guyanensis; bra: L. (V.) braziliensis; pan: L. (V.) panamensis; end: Endotrypanum sp.; try: anuran Trypanosoma sp.; san: sand fly, Lu. ayacuchensis. 
A
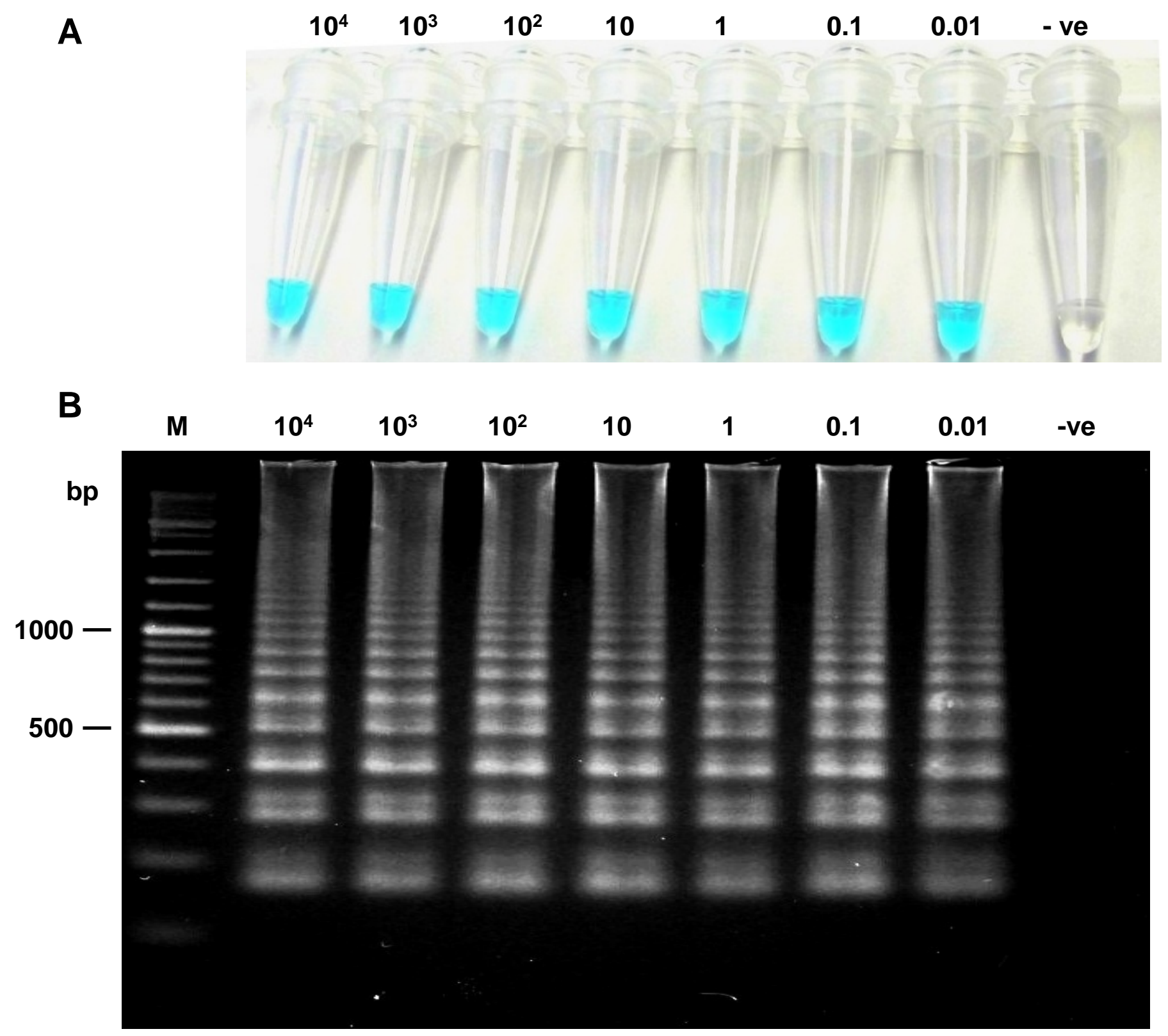

Fig. 1. 
A

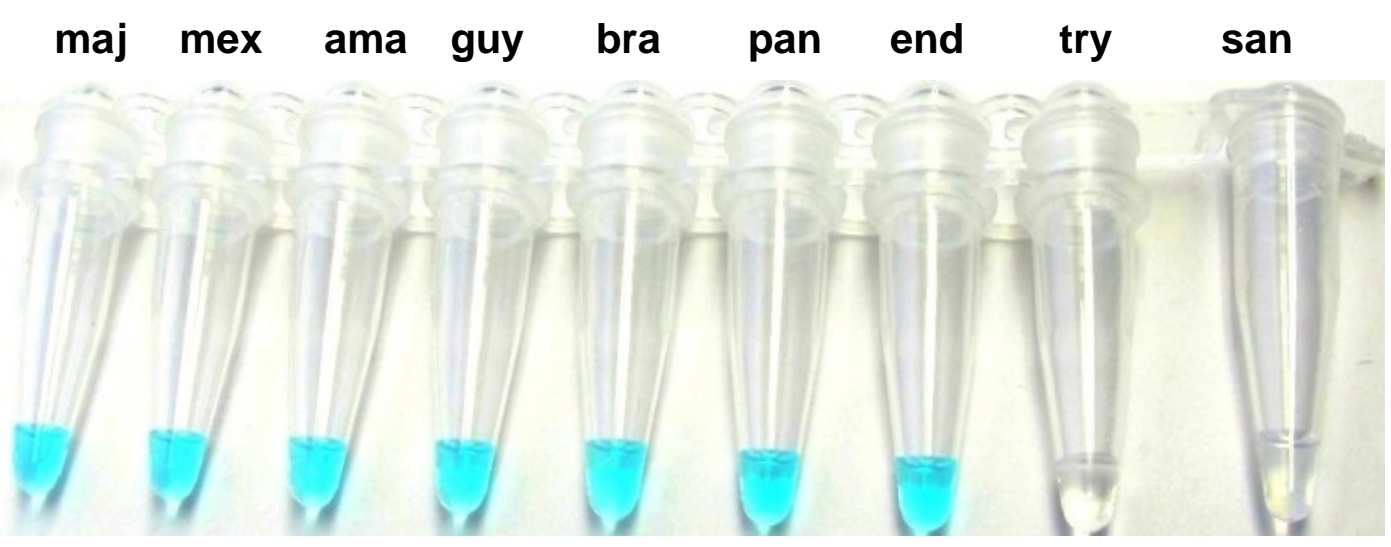

B

M maj mex ama guy bra pan end try san

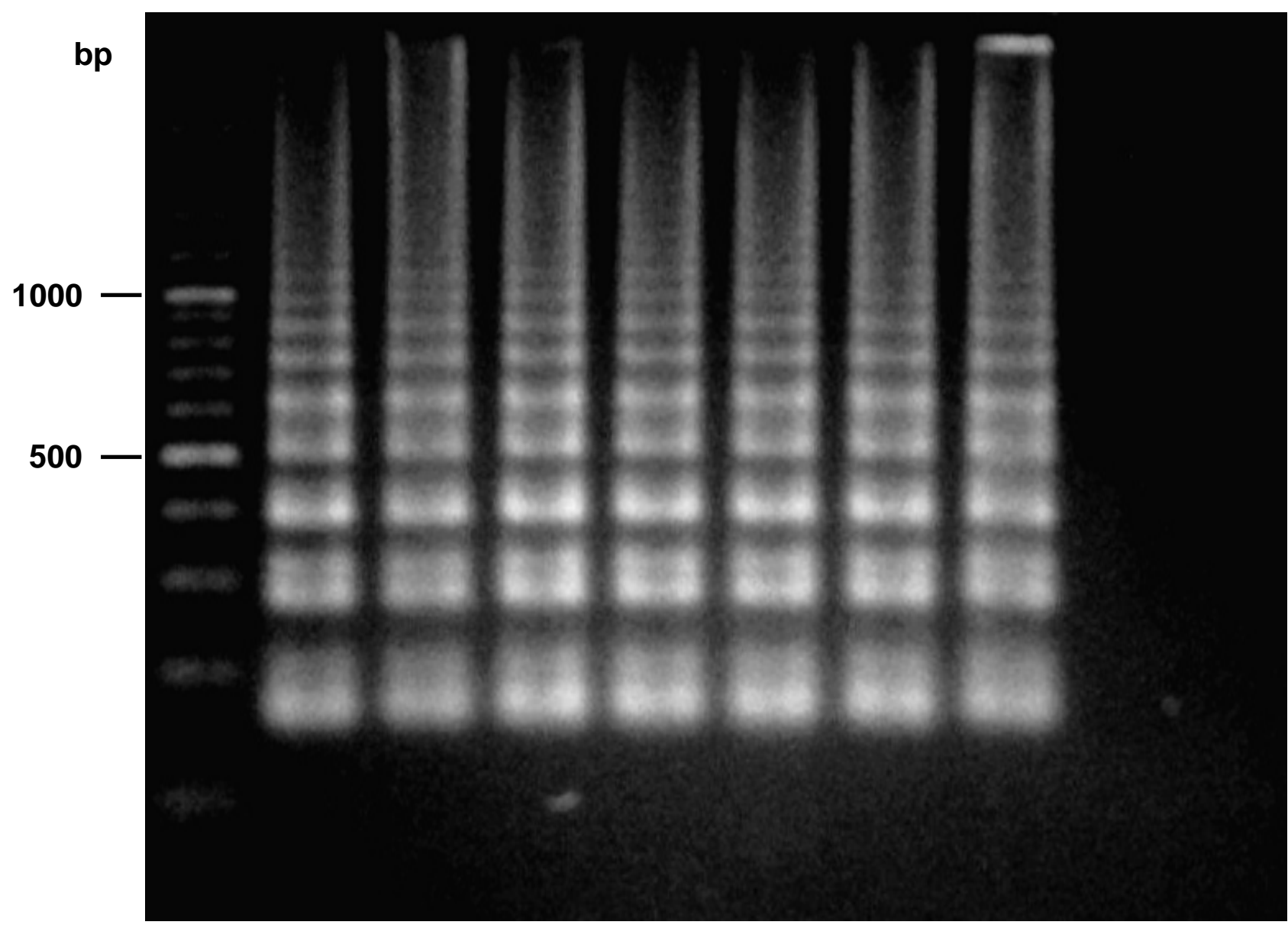

Fig. 2. 